\title{
A Mild and Efficient Method for the Synthesis of Acylals from Aromatic Aldehydes and Their Deprotections Catalyzed by Synthetic Phosphates under Solvent-Free Conditions
}

\author{
Fathallaah Bazi'1, Bahija Mounir², Mohammed Hamza1, Said Sebti \\ ${ }^{1}$ Laboratoire de Chimie Analytique et physicochimie des Matériaux, Université Hassan II, Faculté des Sciences Ben M’Sik, \\ Casablanca, Morocco \\ ${ }^{2}$ Laboratoire Matériaux, Substances Naturelles, Environnement \& Modélisation (LMSNEM), Université Sidi Mohamed Ben \\ Abdellah Fes, Faculté Polydisciplinaire, Taza, Morocco \\ ${ }^{3}$ Laboratoire de Chimie Physique Catalyse et Environnement, Université Hassan II, Faculté des Sciences Ben M’Sik, Casablanca, \\ Morocco \\ Email: fathallaah.bazi@gmail.com
}

How to cite this paper: Bazi, F., Mounir, B., Hamza, M. and Sebti, S. (2018) A Mild and Efficient Method for the Synthesis of Acylals from Aromatic Aldehydes and Their Deprotections Catalyzed by Synthetic Phosphates under Solvent-Free Conditions. Green and Sustainable Chemistry, 8, 334-344.

https://doi.org/10.4236/gsc.2018.84023

Received: September 14, 2018 Accepted: November 27, 2018

Published: November 30, 2018

Copyright (c) 2018 by authors and Scientific Research Publishing Inc. This work is licensed under the Creative Commons Attribution International License (CC BY 4.0).

http://creativecommons.org/licenses/by/4.0/

\begin{abstract}
An efficient and clean preparation of acylals from aromatic aldehydes in the presence of synthetic phosphates (flourapatite and hydroxyapatite doped with $\mathrm{ZnCl}_{2}$ and $\mathrm{ZnBr}_{2}$ ) and acetic anhydride was achieved easily in high yields $(86 \%-97 \%)$ at room temperature under solvent-free conditions. Deprotection of the resulting acylals has also been attained by using the same catalysts under microwave irradiation. This method consistently has advantage of excellent yields ( $82 \%$ - 96\%) and a short reaction time (3 - $4 \mathrm{~min})$.
\end{abstract}

\section{Keywords}

Synthetic Phosphates, Clean Process, Acylals, Protection, Deprotection

\section{Introduction}

There has been an increasing emphasis among researchers from both academia and industry to design synthetic strategies keeping in view the principles of "Green Chemistry" [1]. Adopting the principles of green chemistry means to reduce or eliminate the generation and use of hazardous substances. In recent years, replacement of hazardous solvents with environmentally benign solvents [2] [3] or development of solvent-free syntheses [4] [5] [6] is one of the major focus areas of Green Chemistry. In other cases, the use of heterogeneous cata- 
lysts under solvent-free conditions is becoming very popular as it has many advantages: reduced pollution, reusability, high selectivity, low cost, and simplicity in process and in handling. These factors are especially important in industry.

The 1,1-diacetates (acylals) have been introduced as a suitable protection group for aldehyde because of their remarkable stability to neutral and basic conditions [7]. In addition, they can be converted into other useful functional groups by reaction with appropriate nucleophiles [8] and used as carbonyl surrogates for asymmetric synthesis [9]. 1,1-Diacetates, on the other hand, are ambident substrates containing two types of reactive carbon centres, the carbon atom of the protected aldehyde function and the carbonyl group in the ester moieties [10]. The relative acid stability of 1,1-diacetates is another interesting feature of such 1,1-diacetates in the field of protection-deprotection chemistry [11].

The synthesis of acylals is usually achieved via the reaction of an aldehyde with acetic anhydride $\left(\mathrm{AC}_{2} \mathrm{O}\right)$ in the presence of a protic acid [12] [13] [14], Lewis acids [15]-[23], or heterogeneous catalyst [24]-[30]. Many of reported methods, however, involve strongly acidic or oxidizing conditions, corrosive reagents, high temperature, high catalyst loading, longer reaction time and cumbersome procedures. In view of these, the search for finding a cost-effective, mild and simple protocol for synthesis of acylals from aldehydes is still relevant.

In recent years, we have used the synthetic phosphates (hydroxyapatite (HAP) and fluorapatite (FAP)) alone, doped and modified by metal salts as the heterogeneous catalysts for several reactions, such as Knoevenagel condensation [31] [32], Friedel-Crafts alkylation [33] [34] [35], Michael addition [36] [37], hydration of nitriles to amides [38], and Cross aldol Condensation [39]. In this work, we wish to report a mild, convenient and green methodology for the synthesis and deprotection of acylals from aromatic aldehydes using $\mathrm{ZnCl}_{2} / \mathrm{FAP}$, $\mathrm{ZnBr}_{2} / \mathrm{FAP}, \mathrm{ZnCl}_{2} / \mathrm{HAP}$ and $\mathrm{ZnBr}_{2} / \mathrm{HAP}$.

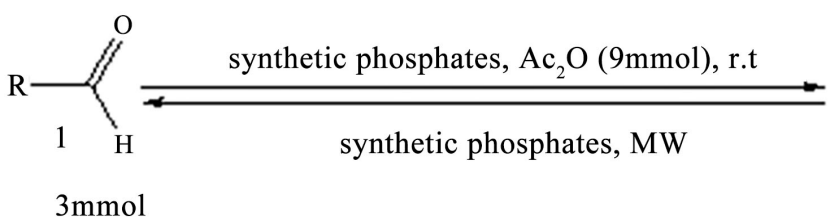

synthetic phosphates $=\mathrm{HAP}, \mathrm{FAP}, \mathrm{ZnCl}_{2} / \mathrm{FAP}, \mathrm{ZnBr}_{2} / \mathrm{FAP}, \mathrm{ZnCl}_{2} / \mathrm{HAP}$ and $\mathrm{ZnBr}_{2} / \mathrm{HAP}$

\section{Results and Discussion}

The catalytic activity of the materials prepared has been evaluated in the protection of aromatic aldehydes. First of all, we have tested the apatite (FAP or HAP) alone in the catalysis of the synthesis of acylals (Table 1). The yields obtained are poor. To enhance the activity of apatite (FAP or HAP), the later was doped with different Lewis acids. For an initial evaluation of the activity of $\mathrm{ZnBr}_{2}$ /apatite 
different experiments were carried out using varying values of catalyst weight in the protection of benzaldehyde with acetic anhydride (Table 1). The yield of product $2 \mathrm{a}$ increased as weight of catalyst increased. This result indicate the positive effect of the catalyst in this transformation, we have chosen $0.1 \mathrm{~g}$ of the catalyst for further study.

To explore the scope of this methodology the protection of different substrates was investigated. To appreciate the important enhancement of the activity of the doped materials, we have carried out synthesis of acylals with $\mathrm{ZnCl}_{2} / \mathrm{FAP}$, $\mathrm{ZnBr}_{2} / \mathrm{FAP}, \mathrm{ZnCl}_{2} / \mathrm{HAP}$ and $\mathrm{ZnBr}_{2} / \mathrm{HAP}$ in the same condition (Table 2). The positive effect of doped solid catalysts can be observed in all cases. The yields obtained are high $(86 \%-97 \%)$ at room temperature except for the product required relatively longer reaction time (entry $2 \mathrm{e}$ ) at $70^{\circ} \mathrm{C}$, possibly owing to the strong electron-withdrawing nitro substituent (see Table 2). Meanwhile, the presence of electron-donating groups (entry $2 \mathrm{~b}, 2 \mathrm{~d}, 2 \mathrm{~g}$, Table 2) increases the yields, demonstrating the participation of both the aldehydes and the acetic anhydride in the rate controlling step of the reaction. Furthermore, $\alpha, \beta$-unsatured aldehydes, such as cinnamaldehyde (Table 2 , product $2 \mathrm{f}$ ) and acid sensitive aldehydes, such as furfural (Table 2, product $2 \mathrm{c}$ ) reacted well without any decomposition or polymerization under the selected reaction conditions.

To evaluate the influence of the metal halide in the activity of the doped material, we have compared the yields obtained in the synthesis of product $2 \mathrm{a}$ using $\mathrm{ZnCl}_{2} / \mathrm{HAP}, \mathrm{ZnBr}_{2} / \mathrm{HAP}, \mathrm{ZnCl}_{2} / \mathrm{FAP}$ and $\mathrm{ZnBr}_{2} / \mathrm{FAP}$. Thus the kinetic curves of these reactions as shown in Figure 1, indicate clearly the promoting effect of Lewis acids, $\mathrm{ZnBr}_{2} / \mathrm{HAP}$ appear to be somewhat the more active catalyst. Reuse of $\mathrm{ZnBr}_{2} / \mathrm{HAP}$ was studied in the synthesis of product $2 \mathrm{a}$. The yields obtained were $94 \%, 76 \%$ and $69 \%$ using the fresh catalyst and reused for the first and the second time, respectively. The decrease of the yields can be explained by the accumulation of organic substrates over the active sites of the catalyst.

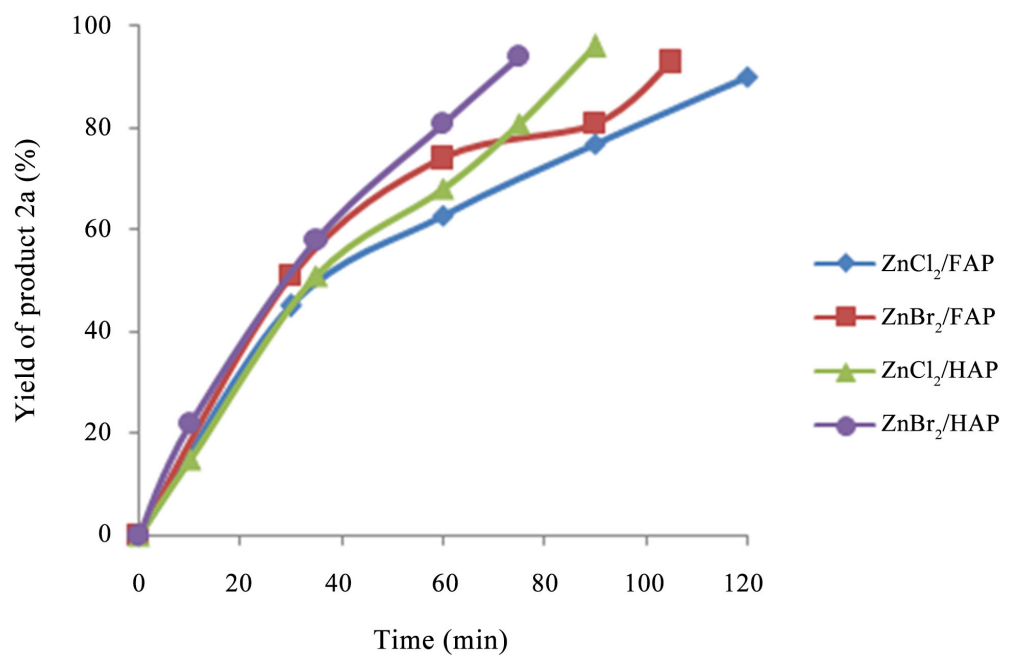

Figure 1. Kinetic curves of product 2a synthesis using HAP and FAP doped with $\mathrm{ZnCl}_{2}$ and $\mathrm{ZnBr}_{2}$. 
Table 1. Effect of the weight of $\mathrm{ZnBr}_{2} / \mathrm{HAP}$ and $\mathrm{ZnBr}_{2} / \mathrm{FAP}$ in the synthesis of product $2 \mathrm{a}$.

\begin{tabular}{ccc}
\hline \multirow{2}{*}{ Weight of catalyst $(\mathrm{g})$} & \multicolumn{2}{c}{ Catalyst Yield (\%) [time (min)] } \\
\cline { 2 - 3 } $\mathrm{ZnBr}_{2} / \mathrm{FAP}$ \\
\hline 0.05 & $53(75)$ & $56(105)$ \\
0.1 & $94(75)$ & $93(105)$ \\
0.2 & $95(75)$ & $96(105)$ \\
0.5 & $95(75)$ & $96(105)$ \\
\hline
\end{tabular}

Table 2. Preparation of 1,1-diacetates from aldehydes.

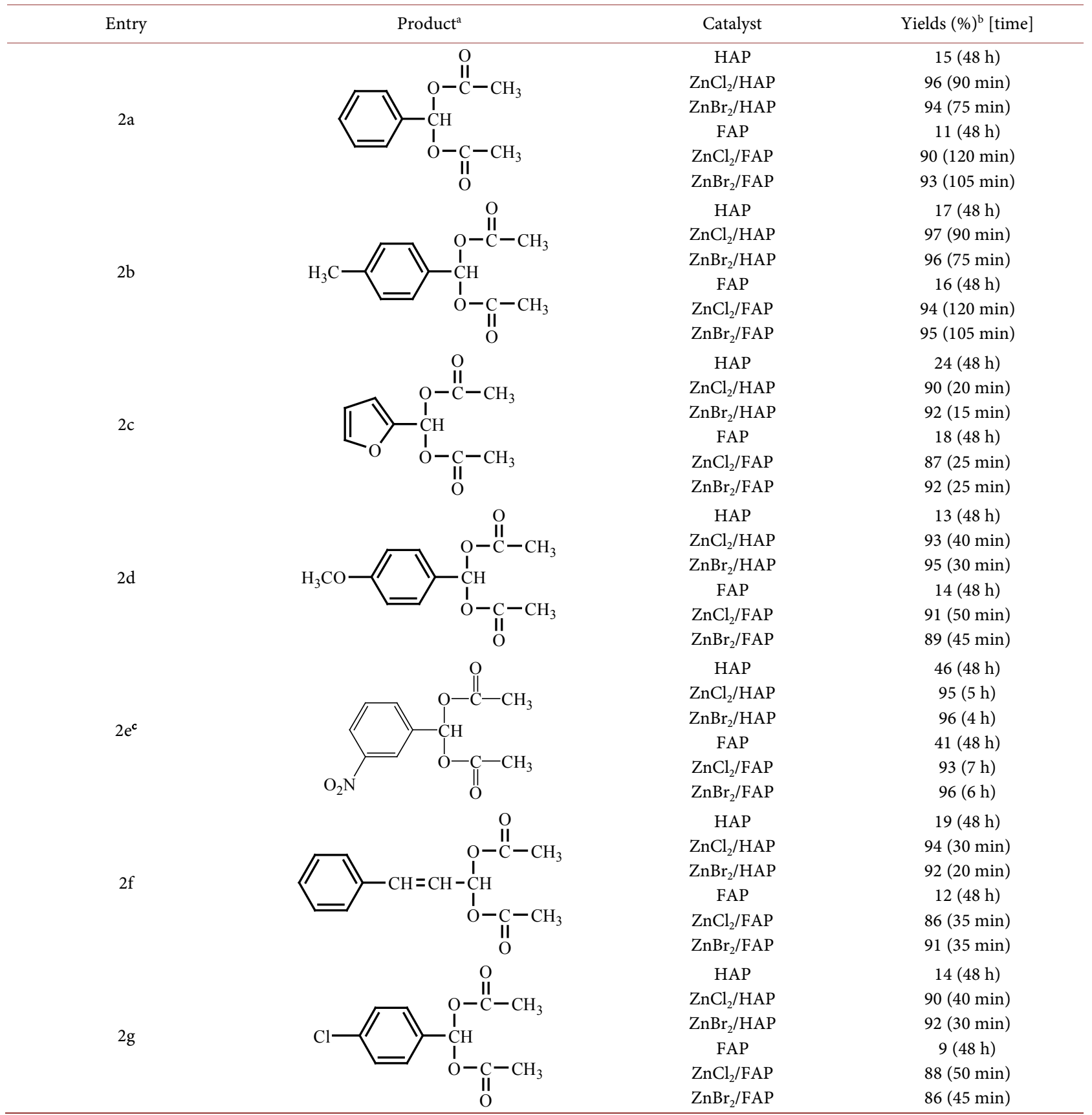

${ }^{\mathrm{a}} \mathrm{All}$ 1,1-diacetates were identified by their ${ }^{1} \mathrm{H}$ NMR, ${ }^{13} \mathrm{C}$ NMR spectra. ${ }^{\mathrm{b}}$ Isolated yield. ${ }^{\mathrm{C}}$ The reaction mixture was stirred at $70^{\circ} \mathrm{C}$. 
Recently, microwave-assisted solvent-free synthesis in organic reactions has been of growing interest as an efficient, economic and clean procedure ("green chemistry") [6] [39] [40] [41] [42]. For these reasons, we have tried the method for deprotection of geminal-diacetates catalyzed by same supports FAP, HAP, $\mathrm{ZnBr}_{2} / \mathrm{FAP}, \mathrm{ZnCl}_{2} / \mathrm{FAP}, \mathrm{ZnBr}_{2} / \mathrm{HAP}$ and $\mathrm{ZnCl}_{2} / \mathrm{HAP}$ ). The results are summarized in Table 3. The reaction were completed within 3 min for

Table 3. Regeneration of aldehydes from 1,1-diacetates.

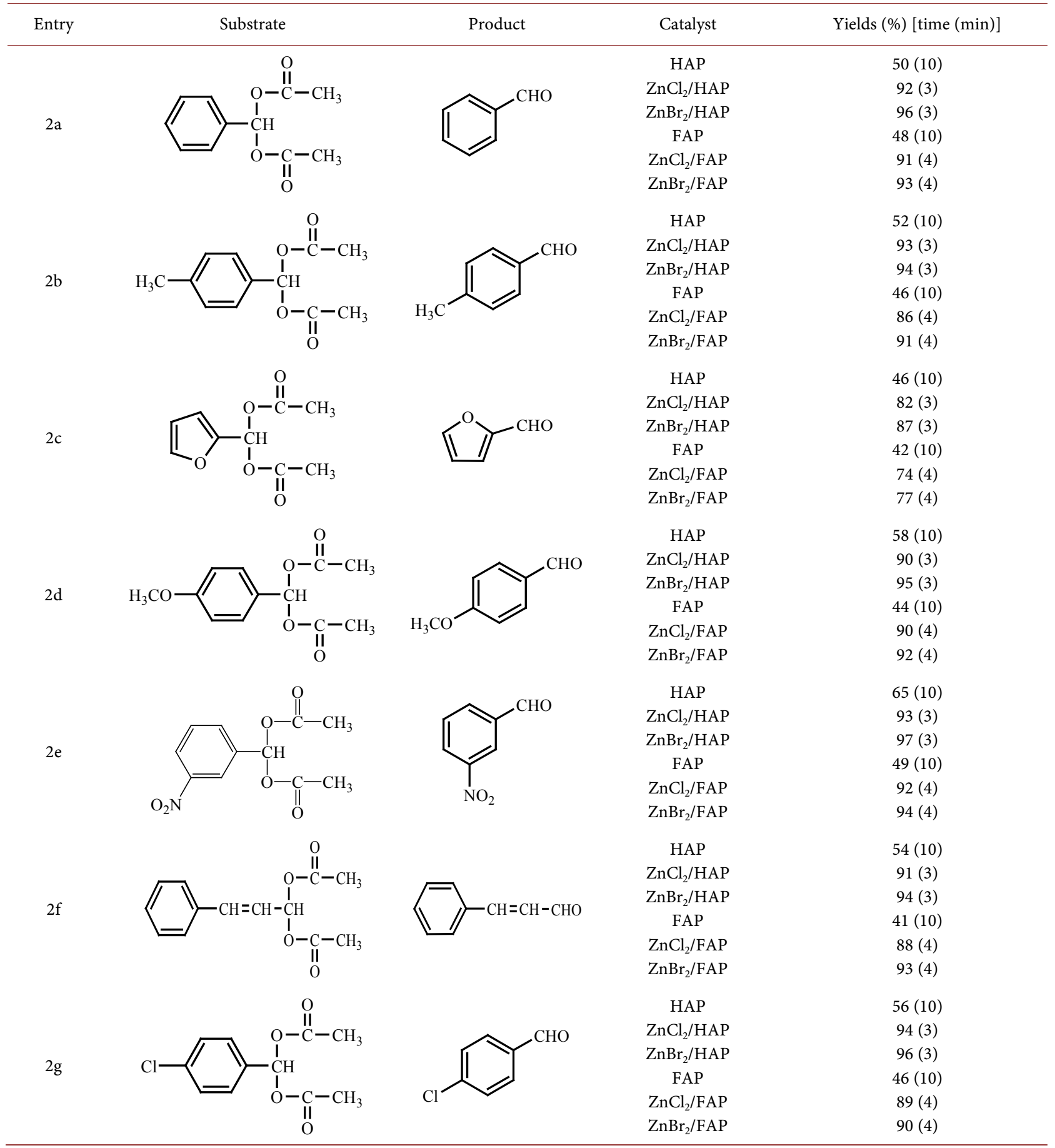


$\mathrm{ZnX}_{2}$ /apatite $(\mathrm{P}=300 \mathrm{~W})$ and high yields $(82 \%$ - 96\%) of regeneration of aldehydes. Whereas, similar reaction in the presence of apatite alone $(\mathrm{P}=500 \mathrm{~W})$ afforded moderate yields of product (49\% - 63\%) within 10 min of irradiation time.

It was noticed that there was no reaction under microwave without catalyst, and to what was observed in traditional heating without solvent. This shows a certain synergy between catalyst and the microwave. It is thus completely reasonable to think that the effect of the temperature is a determining factor to promote this transformation. Unfortunately, domestic microwave was used and therefore it was impossible to measure the exact temperature during the reaction.

In conclusion, we have developed a clean and easy method for the synthesis of geminal-diacetates from aldehydes in solvent free conditions, and regeneration of aromatic aldehydes from the corresponding acylals in microwave irradiation using metal halides doped apatite (HAP or FAP) as heterogeneous catalysts. The positive effect of doping the apatite with $\mathrm{ZnCl}_{2}$ and $\mathrm{ZnBr}_{2}$ has been observed, and the comparison of these materials indicates that $\mathrm{ZnBr}_{2} / \mathrm{HAP}$ is the best catalyst for this reaction. The use of metal halides doped apatite offers diverse advantages including simplicity of operation due to the heterogeneous nature of reaction, easy workup and high yields.

\section{Experimental}

\subsection{Preparation and Characterization of the Catalysts}

\subsubsection{Preparation and Characterization of HAP}

The synthesis of hydroxyapatite [33] is carried out by reaction between diammonium phosphate and calcium nitrate in presence of ammonia. An amount of $250 \mathrm{ml}$ of aqueous solutions containing $7.92 \mathrm{~g}$ of diammonium phosphate, maintained at a $\mathrm{pH}$ greater than 12 by addition of ammonium hydroxide (70 $\mathrm{ml}$ ), were dropped under constant stirring into $150 \mathrm{ml}$ of a solution containing $23.6 \mathrm{~g}$ of calcium nitrate $\left(\mathrm{Ca}\left(\mathrm{NO}_{3}\right)_{2} \mathrm{H}_{2} \mathrm{O}\right)$. The suspension was refluxed for $4 \mathrm{~h}$. Distilled water (DW) was used to prepare the solutions. The obtained hydroxyapatite was filtered, washed with DW, dried overnight at $80^{\circ} \mathrm{C}$ and calcined in air at $800^{\circ} \mathrm{C}$ for $1 \mathrm{~h}$ before use.

The structure of the obtained hydroxyapatite was confirmed by X-ray diffraction, infrared spectroscopy and chemical analysis. The hydroxyapatite crystallized in the hexagonal system with the space group P63/m. The lattice parameters of the prepared HAP are in excellent agreement with standard data: $\mathrm{a}=$ $6.883 \mathrm{~A}^{\circ}$ and $\mathrm{c}=9.422 \mathrm{~A}^{\circ}$. Surface area of the calcined HAP was determined by the BET method from the adsorption-desorption isotherm of nitrogen at its liquid temperature $(77 \mathrm{~K})$, and was found to be $\mathrm{S}=35 \mathrm{~m}^{2} \cdot \mathrm{g}^{-1}$.

\subsubsection{Preparation and Characterization of FAP}

FAP was prepared by the co-precipitation method as previously reported [34]. The structure of the obtained FAP was confirmed by X-ray diffraction, infrared 
spectroscopy and chemical analysis. The fluorapatite crystallized in the hexagonal system with the space group P63/m. The lattice parameters of the prepared FAP are in excellent agreement with standard data: $a=9.364 \mathrm{~A}^{\circ}$ and $\mathrm{c}=$ $6.893 \mathrm{~A}^{\circ}$. Surface area of the calcined FAP was determined by the BET method, and was found to be $S=15 \mathrm{~m}^{2} \cdot \mathrm{g}^{-1}$.

\subsection{Preparation of $\mathrm{ZnX}_{2}$ /Apatite $\left(\mathrm{ZnX}_{2} / \mathrm{HAP}\right.$ or $\left.\mathrm{ZnX}_{2} / \mathrm{FAP}\right)$ $[\mathrm{X}=\mathrm{Br}, \mathrm{Cl}]$}

The preparation of $\mathrm{ZnX}_{2}$ /apatite was as follows: $10 \mathrm{mmol}$ of $\mathrm{ZnX}_{2}$ and $10 \mathrm{~g}$ of apatite (FAP or HAP) were mixed in $100 \mathrm{~mL}$ of water and then evaporated to dryness and dried for $2 \mathrm{~h}$ at $150^{\circ} \mathrm{C}$ before use.

The XRD patterns of $\mathrm{ZnX}_{2} /$ apatite are similar to that of apatite [34] [35] [36]. The modification of the apatite by $\mathrm{ZnX}_{2}$ impregnation does not change the crystalline structure of the solid material. The intensity of typical diffraction peaks did not significantly change indicating no disorganization of the crystalline structure of apatite. It should be noted that no $\mathrm{ZnX}_{2}$ phases were detected on the doped materials in all cases, indicating that $\mathrm{ZnX}_{2}$ was highly dispersed in the solid apatite.

\subsection{Procedure for the Preparation of 1.1-Diacetates}

A typical procedure for the preparation of 1,1-diacetates is a follows: the aldehyde $(3 \mathrm{mmol})$ and acetic anhydride $(9 \mathrm{mmol})$ were placed in a two-necked flask with stirring at room temperature. The catalyst (200 mg of apatite (HAP or FAP) or $100 \mathrm{mg}$ of $\left(\mathrm{ZnX}_{2} / \mathrm{FAP}\right.$ or $\left.\mathrm{ZnX}_{2} / \mathrm{HAP}\right)$ was added and obtained mixture was maintained at room temperature (only for entry $2 \mathrm{e}$ a temperature at $70^{\circ} \mathrm{C}$ was needed) for the appropriate time (see Table 2). After the completion of the reaction was monitored by TLC (hexane/ethyl acetate 5\% - 20\%), $\mathrm{Et}_{2} \mathrm{O}$ was added to the mixture and filtered, and then the catalyst was again washed with $\mathrm{Et}_{2} \mathrm{O}$ and collected for reuse. Evaporation of the solvent followed by column chromatography on silica gel afforded the pure compound corresponding to 1,1-diacetates.

\subsection{Procedure for Deprotection of 1.1-Diacetates}

A typical procedure for the regeneration of aldehydes from 1,1-diacetates is a follows: $0.5 \mathrm{~g}$ of synthetic phosphates were placed, at $500 \mathrm{w}$ for (HAP or FAP) or $350 \mathrm{w}$ for $\left(\mathrm{ZnX}_{2} / \mathrm{FAP}\right.$ or $\left.\mathrm{ZnX}_{2} / \mathrm{HAP}\right)$ in a domestic microwave oven, for the appropriate time (Table 3). After the completion of the reaction was monitored by TLC (hexane/ethyl acetate 5\% - 20\%), $\mathrm{Et}_{2} \mathrm{O}$ was added to the mixture and filtered. Evaporation of the solvent followed by column chromatography on silica gel afforded the pure compound corresponding to aldehydes.

\section{Conflicts of Interest}

The authors declare no conflicts of interest regarding the publication of this paper. 


\section{References}

[1] Anastas, P.T. and Warner, J.C. (1998) Green Chemistry, Theory and Practice. Oxford University Press, Oxford.

[2] Polshettiwar, V. and Varma, R.S. (2008) Microwave-Assisted Organic Synthesis and Transformations Using Benign Reaction Media. Accounts of Chemical Research, 41, 629-639. https://doi.org/10.1021/ar700238s https://pubs.acs.org/doi/abs/10.1021/ar700238s

[3] Polshettiwar, V. and Varma, R.S. (2008) Aqueous Microwave Chemistry: A Clean and Green Synthetic Tool for Rapid Drug Discovery. Chemical Society Reviews, 37, 1546-1557. https://doi.org/10.1039/b716534j http://pubs.rsc.org/en/content/articlelanding/2008/cs/b716534j/unauth\#!divAbstrac $\mathrm{t}$

[4] Toda, F. and Tanaka, K. (2000) Solvent-Free Organic Synthesis. Chemical Reviews, 100, 1025-1074. https://pubs.acs.org/doi/abs/10.1021/cr940089p https://doi.org/10.1021/cr940089p

[5] Varma, R.S. (2002) Clay and Clay-Supported Reagents in Organic Synthesis. Tetrahedron, 58, 1235-1255. https://doi.org/10.1016/S0040-4020(01)01216-9 http://parazite.nn.fi/hiveboard/picproxie_docs/000458467-Tetrahedron_58_2002_1 235-1255.pdf

[6] Varma, R.S. (1999) Solvent-Free Organic Syntheses Using Supported Reagents and Microwave Irradiation. Green Chemistry, 1, 43-55.

http://pubs.rsc.org/en/content/articlehtml/1999/gc/a808223e https://doi.org/10.1039/a808223e

[7] Greene, T.W. and Wuts, P.G.M. (1999) Protective Groups in Organic Synthesis. 3rd Edition, John Wiley and Sons, New York, 306.

[8] Heerden, F.R., Huyser, J.J., Williams, D.B.G. and Holzapfer, C.W. (1998) Palladium-Catalysed Substitution Reactions of Geminal Allylic Diacetates. Tetrahedron Letters, 39, 5281-5284. https://doi.org/10.1016/S0040-4039(98)01000-4 https://www.sciencedirect.com/science/article/pii/S0040403998010004

[9] Trost, B.M. and Lee, C. (2001) Gem-Diacetates as Carbonyl Surrogates for Asymmetric Synthesis. Total Syntheses of Sphingofungins E and F. Journal of the American Chemical Society, 123, 12191-12201.

https://pubs.acs.org/doi/abs/10.1021/ja0118338

https://doi.org/10.1021/ja0118338

[10] Sandberg, M. and Sydnes, L.K. (1998) The Chemistry of Acylals. Part II. Formation of Nitriles by Treatment of Acylals with Trimethylsilyl Azide in the Presence of a Lewis Acid. Tetrahedron Letters, 39, 6361-6364.

https://www.sciencedirect.com/science/article/pii/S0040403998013094 https://doi.org/10.1016/S0040-4039(98)01309-4

[11] Kochhar, K.S., Bal, B.S., Deshpande, R.P., Rajadhyaksha, S.N. and Pinnick, H.W. (1983) Protecting Groups in Organic Synthesis. Part 8. Conversion of Aldehydes into Geminal Diacetates. Journal of Organic Chemistry, 48, 1765-1767. https://pubs.acs.org/doi/abs/10.1021/jo00158a036?journalCode=joceah https://doi.org/10.1021/jo00158a036

[12] Tomita, M., Kikuchi, T., Bessho, K., Hori, T. and Inubushi, Y. (1963) Studies on Pilocereine and Related Compounds. III. Synthesis of 2, 2', 3-Trimethoxydiphenyl Ether-4', 5- and -4', 6-Dicarboxaldehyde. Chemical and Pharmaceutical Bulletin, 11, 1484-1490. https://doi.org/10.1248/cpb.11.1484 https://www.jstage.jst.go.jp/article/cpb1958/11/12/11_12_1484/_article/-char/en 
[13] Davey, W. and Gwilt, J.R. (1957) Chalcones and Related Compounds. Part I. Preparation of Nitro-, Amino-, and Halogeno-Chalcones. Journal of the Chemical Society, 0, 1008-1014. https://doi.org/10.1039/jr9570001008

http://pubs.rsc.org/en/content/articlelanding/1957/jr/jr9570001008/unauth\#!divAbs $\underline{\text { tract }}$

[14] Marshall, J. and Wuts, P.G.M. (1977) Stereoselective Synthesis of Racemic Occidentalol and Related Cis-Fused Hexahydronaphthalenes from M-Toluic Acid. Journal of Organic Chemistry, 42, 1794-1798.

https://pubs.acs.org/doi/abs/10.1021/jo00430a027?journalCode=joceah https://doi.org/10.1021/jo00430a027

[15] Deka, N., Kalita, D.J., Borah, R. and Sarma, J.C. (1997) Iodine as Acetylation Catalyst in the Preparation of 1,1-Diacetates from Aldehydes. Journal of Organic Chemistry, 62, 1563-1564. https://doi.org/10.1021/jo961741e https://pubs.acs.org/doi/abs/10.1021/jo961741e?journalCode=joceah

[16] Scriabire, I. (1961) Nouveau procédé de préparation des aldéhydes dihidrocinnamique. Bulletin de la Société Chimique de France, 1194.

[17] Wang, C.D. and Li, M.H. (2002) A Novel and Efficient Conversion of Aldehydes to 1,1-diacetates Catalyzed with $\mathrm{FeCl}_{3} / \mathrm{SiO}_{2}$ under Microwave Irradiation. Synthetic Communication, 32, 3469-3473. https://doi.org/10.1081/SCC-120014779 https://www.tandfonline.com/doi/abs/10.1081/SCC-120014779

[18] Yadav, J.S., Reddy, B.V.S. and Srinivas, C. (2002) Indium Trichloride Catalyzed Chemoselective Conversion of Aldehydes to gem-Diacetates. Synthetic Communication, 32, 1175-1180. https://www.tandfonline.com/doi/abs/10.1081/SCC-120003607

[19] Yin, L., Zhang, Z.H., Wang, Y.M. and Pang, M.L. (2004) Indium Tribromide as a Highly Efficient and Versatile Catalyst for Chemoselective Synthesis of Acylals from Aldehydes under Solvent-Free Conditions. Synlett, 10, 1727-1730. https://www.thieme-connect.com/products/ejournals/abstract/10.1055/s-2004-8295 $\underline{49}$

[20] Heravi, M.M., Bakhtiari, K., Benmorad, T. and Oskooie, H.A. (2007) $\mathrm{VSO}_{4} 5 \mathrm{H}_{2} \mathrm{O}$ : A Mild and Efficient Catalyst for Chemo-Selective Conversion of Aldehydes to 1,1-Diacetates. Journal of the Chinese Chemical Society, 54, 273-275. https://onlinelibrary.wiley.com/doi/abs/10.1002/jccs.200700040

[21] Karimi, B. and Maleki, J. (2003) Lithium Trifluoromethanesulfonate (LiOTf) as a Recyclable Catalyst for Highly Efficient Acetylation of Alcohols and Diacetylation of Aldehydes under Mild and Neutral Reaction Conditions. Journal of Organic Chemistry, 68, 4951-4954. https://doi.org/10.1021/jo026678+ https://pubs.acs.org/doi/abs/10.1021/jo026678\%2B?journalCode=joceah

[22] Ghosh, R., Maiti, S., Chakraborty, A. and Halder, R. (2004) Indium Triflate: A Reusable Catalyst for Expeditious Chemoselective Conversion of Aldehydes to Acylals. Journal of Molecular Catalysis A: Chemical, 215, 49-53. https://www.sciencedirect.com/science/article/pii/S1381116904000573 https://doi.org/10.1016/j.molcata.2004.01.018

[23] Jin, T.S., Sun, G., Li, Y.W. and Li, T.S. (2002) An Efficient and Convenient Procedure for the Preparation of 1,1-Diacetates from Aldehydes Catalyzed by $\mathrm{H}_{2} \mathrm{NSO}_{3} \mathrm{H}$. Green Chemistry, 4, 255-256. https://doi.org/10.1039/b200219a http://pubs.rsc.org/en/content/articlelanding/2002/gc/b200219a/unauth\#!divAbstra ct

[24] Karimi, B., Ebrahimian, B.G.R. and Seradj, H. (2002) Highly Efficient and Chemoselective Conversion of Aldehydes to Acylals Catalyzed with Tungsten Hexachloride 
(WCl $)_{6}$. Synthetic Communication, 32, 669-673.

https://www.tandfonline.com/doi/abs/10.1081/SCC-120002503 https://doi.org/10.1081/SCC-120002503

[25] Firouzabadi, H., Iranpoor, N., Nowrouzi, F. and Amani, K. (2003) Aluminum Dodecatungstophosphate $\left(\mathrm{AlPW}_{12} \mathrm{O}_{40}\right)$ as an Efficient Heterogeneous Inorganic Catalyst for the Chemoselective Synthesis of Geminal Diacetates (Acylals) under Solvent-Free Conditions. Tetrahedron Letters, 44, 3951-3954.

https://www.sciencedirect.com/science/article/pii/S0040403903008116 https://doi.org/10.1016/S0040-4039(03)00811-6

[26] Romanelli, G.P., Thomas, H.J., Baronetti, G.T. and Autino, J.C. (2003) Solvent-Free Catalytic Preparation of 1,1-Diacetates from Aldehydes Using a Wells-Dawson Acid $\left(\mathrm{H}_{6} \mathrm{P}_{2} \mathrm{~W}_{18} \mathrm{O}_{62} \cdot 24 \mathrm{H}_{2} \mathrm{O}\right)$. Tetrahedron Letters, 44, 1301-1303. https://www.sciencedirect.com/science/article/pii/S0040403902028174 https://doi.org/10.1016/S0040-4039(02)02817-4

[27] Curini, M., Epifano, F., Marcotullio, M.C., Rosati, O. and Nocchetti, M. (2002) Preparation and Deprotection of 1,1-Diacetates (Acylals) Using Zirconium Sulfophenyl Phosphonate as Catalyst. Tetrahedron Letters, 43, 2709-2711. https://www.sciencedirect.com/science/article/pii/S0040403902003696 https://doi.org/10.1016/S0040-4039(02)00369-6

[28] Smitha, G. and Reddy, C.S. (2003) A Facile and Efficient $\mathrm{ZrCl}_{4}$ Catalyzed Conversion of Aldehydes to Geminal-Diacetates and Dipivalates and Their Cleavage. Tetrahedron, 59, 9571-9576. https://doi.org/10.1016/j.tet.2003.10.002 https://www.sciencedirect.com/science/article/pii/S0040402003015813

[29] Ziyaei, A., Azizi, N. and Saidi, M.R. (2005) Chemoselective and Convenient Preparation of 1,1-Diacetates from Aldehydes, Mediated by Solid Lithium Perchlorate under Solvent-Free Conditions. Journal of Molecular Catalysis A: Chem, 238, 138-141. https://doi.org/10.1016/j.molcata.2005.05.022 https://www.sciencedirect.com/science/article/pii/S138111690500364X

[30] Sebti, S., Tahir, R., Nazih, R., Saber, A. and Boulaajaj, S. (2002) Hydroxyapatite as a New Solid Support for the Knoevenagel Reaction in Heterogeneous Media without Solvent. Applied Catalysis A, 228, 155-159. https://www.sciencedirect.com/science/article/pii/S0926860X01009619 https://doi.org/10.1016/S0926-860X(01)00961-9

[31] Sebti, S., Nazih, R., Tahir, R., Salhi, L. and Saber, A. (2000) Fluorapatite: New Solid Catalyst of the Knoevenagel Reaction in Heterogeneous Media without Solvent. Applied Catalysis A, 197, L187-L190. https://doi.org/10.1016/S0926-860X(99)00492-5 https://www.sciencedirect.com/science/article/pii/S0926860X99004925

[32] Sebti, S., Tahir, R., Nazih, R. and Boulaajaj, S. (2001) Comparison of Different Lewis Acid Supported on Hydroxyapatite as New Catalysts of Friedel-Crafts Alkylation. Applied Catalysis A: General, 218, 25-30. https://www.sciencedirect.com/science/article/pii/S0926860X01005993 https://doi.org/10.1016/S0926-860X(01)00599-3

[33] Saber, A., Smahi, A., Solhy, A., Nazih, R., Elaabar, B., Maizi, M. and Sebti, S. (2003) Heterogeneous Catalysis of Friedel-Crafts Alkylation by the Fluorapatite Alone and Doped with Metal Halides. Journal of Molecular Catalysis A, 202, 229-237. https://www.sciencedirect.com/science/article/pii/S1381116903001869 https://doi.org/10.1016/S1381-1169(03)00186-9

[34] Tahir, R., Banert, K. and Sebti, S. (2006) Natural and Synthetic Phosphates: New and Clean Heterogeneous Catalysts for the Synthesis of 5-Arylhydantoins. Applied 
Catalysis A: General, 298, 261-264. https://doi.org/10.1016/j.apcata.2005.09.024 https://www.sciencedirect.com/science/article/pii/S0926860X05007222

[35] Tahir, R., Banert, K., Solhy, S. and Sebti, S. (2006) Zinc Bromide Supported on Hydroxyapatite as a New and Efficient Solid Catalyst for Michael Addition of Indoles to Electron-Deficient Olefins. Journal of Molecular Catalysis A, 246, 39-42. https://www.sciencedirect.com/science/article/pii/S1381116905007259 https://doi.org/10.1016/j.molcata.2005.10.012

[36] Zahouily, M., Mounir, B., Charki, H., Mezdar, A., Bahlaouan, B. and Ouammou, M. (2006) Investigation of the Basic Catalytic Activity of Natural Phosphates in the Michael Condensation. Arkivoc, 13, 178-186.

https://www.arkat-usa.org/get-file/22824/

[37] Bazi, F., El Badaoui, H., Tamani, S., Sokori, S., Solhy, A., Macquarrie, D.J. and Sebti, S. (2006) A Facile Synthesis of Amides by Selective Hydration of Nitriles Using Modified Natural Phosphate and Hydroxyapatite as New Catalysts. Applied Catalysis $A$, 301, 211-214. https://doi.org/10.1016/j.apcata.2005.12.003

[38] https://www.sciencedirect.com/science/article/pii/S0926860X05009269

[39] Mounir, B., Bazi, F., Mounir, A., Toufik, H. and Zahouily, M. (2018) Sodium-Modified Fluorapatite: A Mild and Efficient Reusable Catalyst for the Synthesis of $\alpha, \alpha^{\prime}$-Bis(Substituted Benzylidene) Cycloalkanones under Conventional Heating and Microwave Irradiation. Green and Sustainable Chemistry, 8, 156-166. http://www.scirp.org/journal/PaperInformation.aspx?paperID=84414 https://doi.org/10.4236/gsc.2018.82011

[40] Lidstrom, P., Tierney, J., Wathey, B. and Westman, J. (2001) Microwave Assisted Organic Synthesis. Tetrahedron, 57, 925-9283.

https://www.erowid.org/archive/rhodium/pdf/microwave.organic.chemistry.review. pdf https://doi.org/10.1016/S0040-4020(01)00906-1

[41] Rezayati, S., Hajinasiri, R. and Erfani, Z. (2016) Microwave-Assisted Green Synthesis of 1,1-Diacetates (acylals) Using Selectfluor ${ }^{\mathrm{TM}}$ as an Environmental Friendly Catalyst under Solvent-Free Conditions. Research on Chemical Intermediates, 42, 2567-2576. https://doi.org/10.1007/s11164-015-2168-1 https://link.springer.com/article/10.1007/s11164-015-2168-1

[42] Naeimi, H., Kiani, F. and Moradian, M. (2018) Rapid Microwave Promoted Heterocyclization of Primary Amines with Triethyl Orthoformate and Sodium Azide Using Zinc Sulfide Nanoparticles as Recyclable Catalyst. Green Chemistry Letters and Reviews, 11, 361-369. https://doi.org/10.1080/17518253.2018.1510990 https://www.tandfonline.com/doi/pdf/10.1080/17518253.2018.1510990 